\title{
Prognostic Value of Metabolic Response Measured by FDG-PET-CT in Patients with Breast Cancer Liver Metastasis Treated with Stereotactic Body Radiotherapy
}

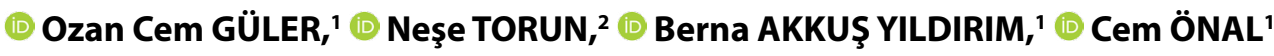 \\ 'Department of Radiation Oncology, Başkent University Faculty of Medicine, Adana-Turkey \\ ${ }^{2}$ Department of Nuclear Medicine, Başkent University Faculty of Medicine, Adana-Turkey
}

\begin{abstract}
OBJECTIVE
To investigate the impact of metabolic response measured by 18 -fluorodeoxyglucose positron emission tomography and computed tomography (FDG-PET-CT) in patients with breast cancer liver metastasis (BCLM) treated with stereotactic body radiotherapy (SBRT).

\section{METHODS}

The medical records of 17 patients with BCLM treated with SBRT between March 2013 and October 2017 were investigated retrospectively. Patients received SBRT for their liver metastasis, and thereafter, a second FDG-PET-CT was performed for response assessment in a median of 4.1 (2.2-8.2) months. A total of 54 Gy in three fractions were delivered to liver metastatic lesions. The standardized uptake value (SUV) and survival rates were evaluated.

\section{RESULTS}

After a median follow-up time of 11.5 (3.2-48.9) months, there was a significant difference between preand post-SBRT SUVs $(\mathrm{p}<0.001)$. Complete metabolic response was observed in $14(82 \%)$ patients, partial metabolic response was observed in $2(12 \%)$ patients, and stable metabolic disease/progressive metabolic disease was observed in $1(6 \%)$ patient at post-treatment PET-CT. The 1- and 2-year overall survival rates were $68 \%$ and $57 \%$, respectively, and the 1 - and 2 -year progression-free survival rates were $38 \%$ and $25 \%$, respectively.
\end{abstract}

\section{CONCLUSION}

PET-CT is an effective tool for response monitoring in patients with BCLM treated with SBRT.

Keywords: Breast cancer; liver metastasis; positron emission tomography; stereotactic body radiotherapy. Copyright $\odot$ 2018, Turkish Society for Radiation Oncology

\section{Introduction}

The liver is one of the most common metastatic sites for many cancer types, and liver metastasis (LM) is a substantial cause of morbidity and mortality.[1] Local treatment options for LM are surgery, transarterial chemoembolization (TACE), radiofrequency ablation
(RFA), and radiotherapy (RT). These local treatments could be applied alone or as an adjunct to systemic chemotherapeutic agents in order to improve outcomes. $[2,3]$

Patients with breast cancer with metastasis had dismal 5-year survival rates of approximately 25\%.[4] Of those, patients with liver or brain metastasis have worse
Dr. Ozan Cem GÜLER

Başkent Üniversitesi,

Tıp Fakültesi,

Radyasyon Onkolojisi Anabilim Dalı,

Adana-Turkey

E-mail: ocguler@gmail.com 
outcomes compared with bone or lung metastasis, with a median survival of 4-8 months if left untreated. $[5,6]$ Oligometastatic state is common in patients with breast cancer, and the outcomes of these patients are better than those with diffuse metastatic disease with effective local and systemic treatment strategies.[7] Furthermore, the innovations of imaging modalities led to early diagnosis of patients with oligometastasis that may potentially improve treatment outcomes. [7]

Although RT had been used only for palliative intent in patients with metastasis previously, the role of RT had been evolved from palliative to curative approach especially in patients with oligometastasis. Stereotactic body radiotherapy (SBRT) is a high precision, non-invasive RT technique that allows higher radiation doses with a steep dose gradient and could be delivered safely to the liver without causing functional compromise.[8] The feasibility of SBRT for LM had been shown in various trials, with reported local control (LC) rates up to $90 \%$ per acceptable toxicity.[9-12]

The prognostic value of 18-fluorodeoxyglucose positron emission tomography and computed tomography (FDG-PET-CT) had been shown in various tumor types.[13-15] However, its role in patients with oligometastatic breast cancer liver metastasis (BCLM) treated with SBRT is still under investigation. Hence, we sought to investigate the impact of metabolic response measured by FDG-PET-CT in patients with BCLM treated with SBRT and systemic treatment.

\section{Materials and Methods}

\section{Patients}

The medical records of 17 patients with BCLM treated with SBRT between March 2013 and October 2017 were investigated retrospectively. Patients had LM either at diagnosis or as a disease progression after curative treatment. Only in patients with $\leq 5$ metastasis or primary tumor remained under control, SBRT to LM was performed. Patient selection criteria included maximum LM diameter $<6 \mathrm{~cm}$, Karnofsky Performance Status $\geq 70$, normal coagulation function tests, ChildPugh Status A-B, and life expectancy $>3$ months. The FDG-PET-CT was performed in all of the patients before liver SBRT and a median of $4.1(2.2-8.2)$ months after completion of liver SBRT. Treatment response was performed according to "PET Response Criteria in Solid Tumors" (PERCIST) for all patients [16] (Fig. 1). Complete metabolic response (CMR) was accepted if all FDG-avid lesions disappeared. Significant reduction in the standardized uptake values (SUVs) was accepted as partial metabolic response (PMR). Stable (SMD) or progressive metabolic disease (PMD) was accepted if there was no visible change or unequivocal progression of the primary tumor.

\section{FDG-PET-CT}

Patients were imaged using a dedicated PET/CT system (Discovery-STE 8; General Electric Medical System, Milwaukee, WI, USA) as previously described. [17] Briefly, patients fasted for at least $6 \mathrm{~h}$ before intravenous administration of 370 to $555 \mathrm{MBq}(10 \mathrm{Y} 15 \mathrm{mCi})$ FDG. Pre-injection blood glucose levels were measured to ensure that they were $<150 \mathrm{mg} / \mathrm{dL}$. During the distribution phase, patients were in supine position in a quiet room. Combined image acquisition started 60 min after FDG injection. Patients were scanned on a flat-panel carbon fiber composite table insert. First, an unenhanced CT scan (5-mm slice thickness) from the base of the skull to the inferior border of the pelvis was
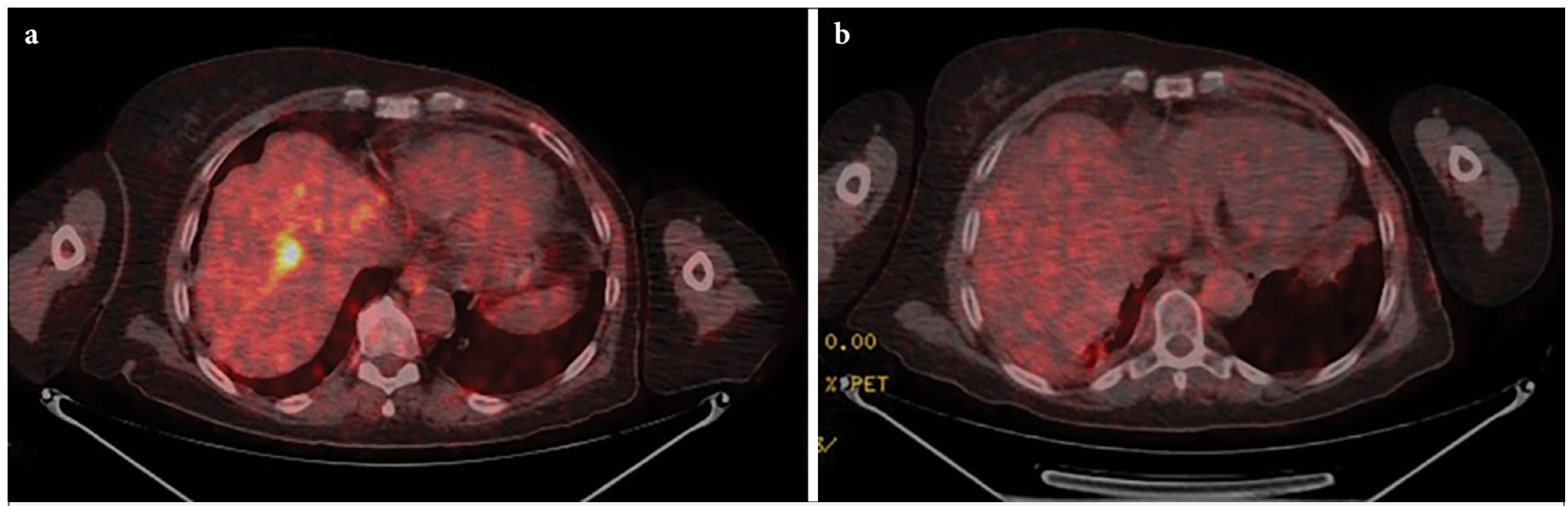

Fig. 1. (a) The positron emission tomography (PET-CT) images of a representative patient demonstrating liver metastasis with SUVmax of 12.4. (b) Complete metabolic response observed at PET-CT images obtained 3.4 months after completion of liver stereotactic radiotherapy. 
obtained using a standardized protocol $(140 \mathrm{kV}$ and $80 \mathrm{~mA}$ ). The subsequent PET scan was acquired in a three-dimensional mode from the base of the skull to the inferior border of the pelvis (6-7 bed positions, 3 min per bed position) without repositioning the patient on the table. CT and PET images were obtained with the patient breathing shallowly. Attenuation was corrected using the CT images. Areas of FDG uptake were categorized as malignant based on location, intensity, shape, size, and visual correlation with CT images to differentiate physiological uptake from pathological uptake.

\section{SBRT technique}

Patients underwent $1.25 \mathrm{~mm}$ multislice contrast-enhanced planning CT from tracheal bifurcation to the lower border of the kidneys for simulation (Optima 580; GE Healthcare, Waukesha, WI, USA). Patients were positioned supine with arms above the head and immobilized using a BodyFIX ${ }^{\oplus}$ bluebag with vacuum wrap (Elekta, Stockholm, Sweden). In addition, an abdominal compress was used to minimize organ motions.

Magnetic resonance imaging and FDG-PET-CT were fused with planning CTs to help the clinicians to localize the target volume precisely, where appropriate. Gross tumor volume (GTV) included the visible tumor in imaging, but no clinical tumor volume was defined. Planning tumor volume (PTV) was expanded $7 \mathrm{~mm}$ in all directions except for $12 \mathrm{~mm}$ craniocaudal margin. $[12,18]$ No fiducial markers were implanted before treatment planning.
A healthy liver was calculated as liver volume minus GTV. In addition to the liver, other organs at risk (OARs) under consideration were the spinal cord, kidneys, stomach, duodenum, heart, small bowel, esophagus, and ribs according to the location of the lesion. The prescribed dose was 54 Gy delivered in three fractions, and the dose was prescribed to $90 \%$ isodose line. Treatment was delivered every other day. PTV coverage was aimed at $>95 \%$ of the prescribed dose (Fig. 2).

Plans were calculated by the Monaco Treatment Planning System (Elekta Ltd., Crawley, UK) using the Monte Carlo algorithm and a sliding window multileaf collimator delivery technique. All treatment plans were performed for delivery using an Axesse linear accelerator (Elekta AB, Stockholm, Sweden). Volumetric modulated arc therapy plans consisted of double or triple $360^{\circ}$ arcs.

Previously published OAR dose constraints during liver SBRT were used. [12,19] At least $700 \mathrm{~mL}$ of healthy liver should receive $<15 \mathrm{~Gy}$ in three fractions. Other dose constraints of OARs included total kidney volume $<15$ Gy (volume receiving 15 Gy should be $<35 \%$ ), maximum dose (D1cc) for spinal cord $<18 \mathrm{~Gy}$, D1cc for duodenum $<21 \mathrm{~Gy}$, D1cc for small bowel $<21 \mathrm{~Gy}$, D1cc for esophagus $<21 \mathrm{~Gy}$, D1cc for stomach $<21 \mathrm{~Gy}$, D1cc for heart $<30 \mathrm{~Gy}$, and D1cc for ribs $<30 \mathrm{~Gy}$.

\section{Statistical analysis}

Statistical analyses were performed using the SPSS 22.0 software (SPSS, Chicago, IL, USA). The LC, overall survival (OS), and progression-free survival (PFS) rates
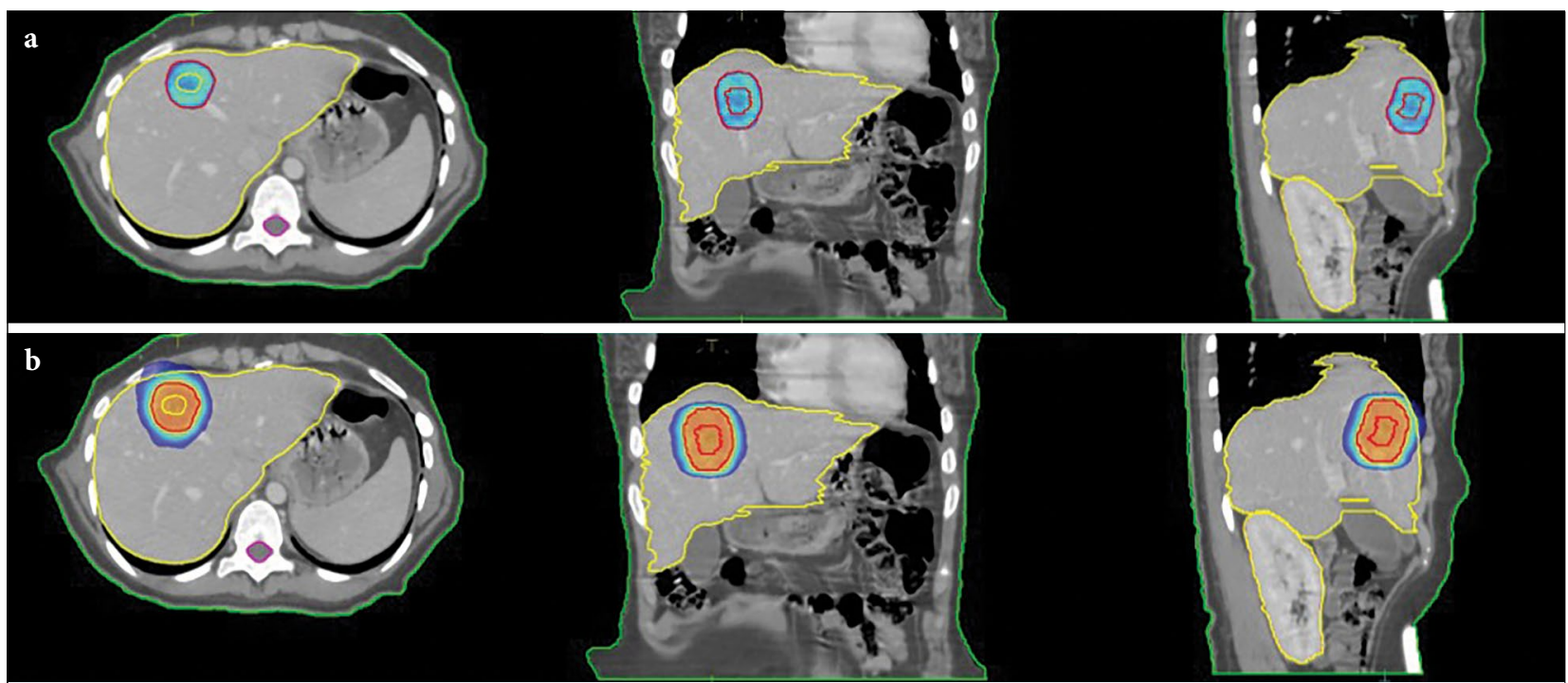

Fig. 2. The images of a representative patient at axial, coronal, and sagittal images demonstrating (A) $95 \%$ and (B) $50 \%$ of isodose of prescribed doses. 
were calculated using the Kaplan-Meier analyses. OS was defined from the date of LM diagnosis until death or the last follow-up visit, and PFS was calculated as the time between LM diagnosis time and any disease progression or death. Local failure was scored according to the PERCIST criteria. Statistical analysis was performed to compare the initial SUV with the values after SBRT. All p-values reported are two-sided. A pvalue $<0.05$ was considered significant.

\section{Results}

\section{Clinical characteristics}

All patients were female, and the median age was 44 (27-67) years. The primary tumor histology was invasive ductal carcinoma. Mastectomy was performed in all patients. Fifteen (88\%) patients received postoperative RT for primary tumor. Three (18\%) patients were treated with neoadjuvant systemic therapy prior to surgery, whereas $14(82 \%)$ patients received postoperative systemic chemotherapy. The immunohistochemical analysis of estrogen receptor (ER), progesterone receptor [20], and cerb-B2 for the entire cohort revealed that $14(82 \%)$ patients had ER (+), 10 patients had PR $(+)$, and $5(29 \%)$ patients had cerb-B2 $(+)$ disease. Only 1 (6\%) patient had triple negative disease.

\section{Patient outcomes and survival}

Table 1 shows the patient characteristics. Three (18\%) patients had de novo LM, whereas 14 (82\%) patients had LM during the follow-up period. Eleven (65\%) patients had only LM, whereas 6 (35\%) patients had more than one metastatic site. LM was observed at a median of 28.3 (0-104.5) months.

After a median follow-up time of 11.5 (3.2-48.9) months, 9 (53\%) patients had distant disease recurrence. Disease progression was observed at a median of $8(0.8-32.8)$ months after completion of liver SBRT. At the last follow-up, $1(6 \%)$ patient was alive with no evidence of disease, 9 (53\%) patients were alive with disease, and 7 (41\%) patients died due to disease progression. The 1- and 2-year OS rates were $68 \%$ and $57 \%$, respectively, and the 1 - and 2-year PFS rates were $38 \%$ and $25 \%$, respectively (Fig. 3 ).

There were no grade 4 or 5 toxicities observed. However, mild to moderate dizziness was seen during the SBRT period and disappeared at the end of treatment. Furthermore, there was no radiation-induced liver disease observed.

\section{PET analysis}

The median pre-SBRT SUVmax of LM was 6.88 (range: 4.06-16.10), and the median post-SBRT SUVmax was 0 (range: $0-5.30$ ). There was a significant difference between pre- and post-SBRT SUVs $(\mathrm{p}<0.001)$. CMR was observed in 14 (82\%) patients, PMR was observed in 2 (12\%) patients, and SMD/PMD was observed in $1(6 \%)$ patient at post-treatment PET-CT.

\begin{tabular}{|c|c|c|c|c|c|c|c|c|}
\hline Patient & $\begin{array}{c}\text { Age } \\
\text { (years) }\end{array}$ & $\begin{array}{l}\text { Tumor } \\
\text { stage }\end{array}$ & $\begin{array}{l}\text { LM } \\
\text { timing }\end{array}$ & $\begin{array}{c}\text { Other } \\
\text { metastatic sites }\end{array}$ & $\begin{array}{l}\text { Primary } \\
\text { treatment }\end{array}$ & $\begin{array}{l}\text { Adjuvant } \\
\text { treatment }\end{array}$ & $\begin{array}{c}\text { OS } \\
\text { (months) }\end{array}$ & $\begin{array}{c}\text { PFS } \\
\text { (months) }\end{array}$ \\
\hline 1 & 27 & TxNx & de novo & Lung & $\mathrm{S}, \mathrm{C}, \mathrm{R}$ & $C$ & 4.90 & .83 \\
\hline 2 & 31 & $\mathrm{~T} 2 \mathrm{~N} 1$ & progression & Bone & $S, C, R$ & $\mathrm{C}, \mathrm{H}$ & 15.43 & 9.10 \\
\hline 3 & 32 & $\mathrm{~T} 2 \mathrm{~N} 3$ & progression & Lung & $\mathrm{S}, \mathrm{C}, \mathrm{R}$ & Xeloda & 48.87 & 12.63 \\
\hline 4 & 34 & $\mathrm{~T} 2 \mathrm{~N} 2$ & progression & Bone & $\mathrm{S}, \mathrm{C}$ & C & 8.97 & 8.97 \\
\hline 5 & 36 & T4N1 & progression & Lung & $\mathrm{S}, \mathrm{C}, \mathrm{R}$ & $\mathrm{C}$ & 6.87 & 6.87 \\
\hline 6 & 37 & T2N3 & progression & Bone & $\mathrm{S}, \mathrm{C}, \mathrm{R}$ & C & 11.87 & 1.67 \\
\hline 7 & 38 & TxN2 & progression & Bone & $\mathrm{S}, \mathrm{C}, \mathrm{R}$ & $\mathrm{C}$ & 7.47 & 7.47 \\
\hline 8 & 40 & T2N2 & progression & Bone & $S, C$ & $\mathrm{C}, \mathrm{H}$ & 32.77 & 32.77 \\
\hline 9 & 44 & T3N2 & progression & Lung & $\mathrm{S}, \mathrm{C}, \mathrm{R}$ & $\mathrm{H}$ & 25.87 & 9.70 \\
\hline 10 & 49 & T1N0 (bilat.) & progression & None & $\mathrm{S}, \mathrm{C}, \mathrm{R}$ & Vinorelbin & 8.93 & 6.20 \\
\hline 11 & 52 & T3N1 & progression & Bone & $\mathrm{S}, \mathrm{C}, \mathrm{R}$ & C & 11.17 & 10.63 \\
\hline 12 & 52 & $\mathrm{~T} 2 \mathrm{~N} 2$ & progression & None & $\mathrm{S}, \mathrm{C}, \mathrm{R}$ & $\mathrm{C}, \mathrm{H}$ & 25.83 & 3.90 \\
\hline 13 & 52 & T2N3 & progression & Bone & $\mathrm{S}, \mathrm{C}, \mathrm{R}$ & C & 5.83 & 5.83 \\
\hline 14 & 55 & T3NO & progression & None & $S, C, R$ & - & 12.83 & 12.83 \\
\hline 15 & 63 & TxN2 & progression & Bone & $\mathrm{S}, \mathrm{C}, \mathrm{R}$ & $\mathrm{C}, \mathrm{H}$ & 3.20 & 3.20 \\
\hline 16 & 65 & TxN2 & progression & Lung & $\mathrm{S}, \mathrm{C}, \mathrm{R}$ & xeloda & 11.53 & 11.53 \\
\hline 17 & 67 & TxN2 & progression & Lung & $\mathrm{S}, \mathrm{C}, \mathrm{R}$ & $\mathrm{H}$ & 28.70 & 8.03 \\
\hline
\end{tabular}



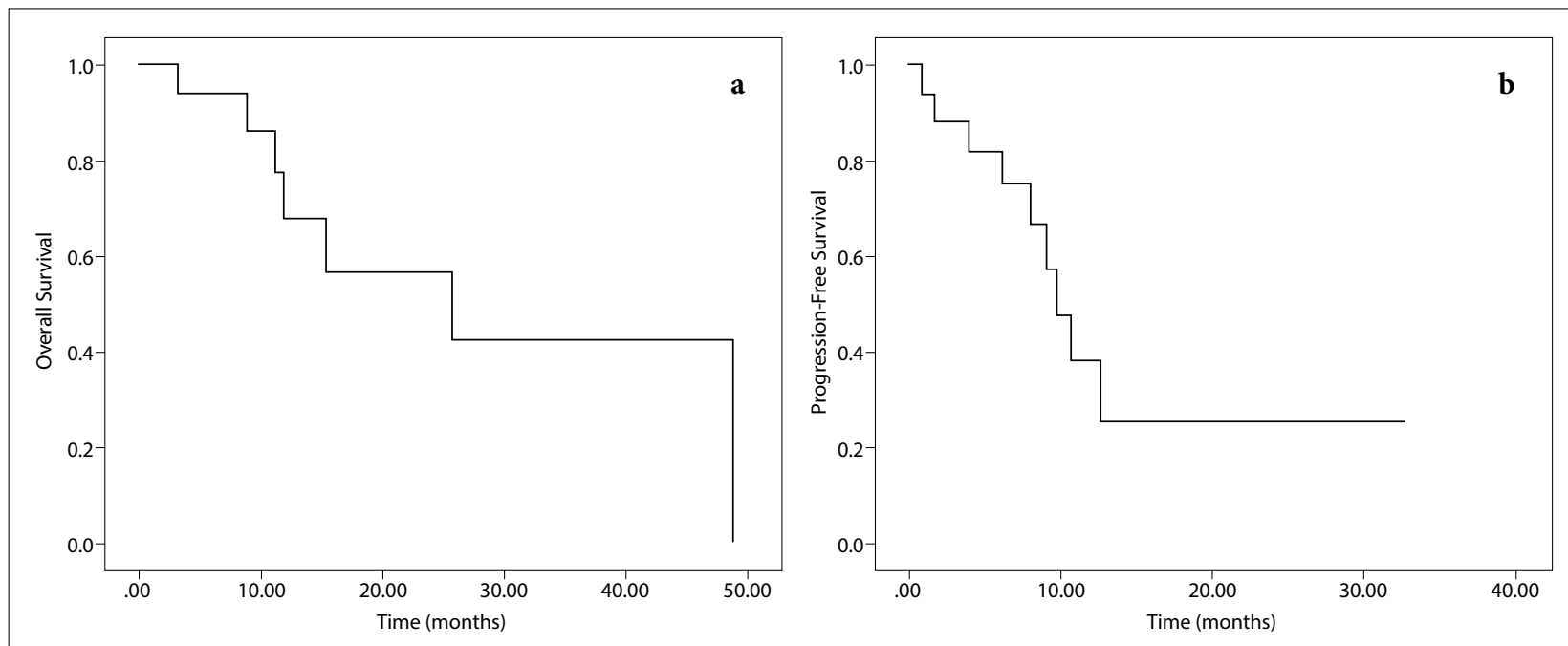

Fig. 3. Kaplan-Meier curves demonstrating (a) overall survival and (b) progression-free survival.

\section{Discussion}

In the current study, we demonstrated that PET-CT is an effective tool for response monitoring in patients with BCLM treated with SBRT. The 1- and 2-year OS rates for patients with BCLM treated with liver SBRT and systemic chemotherapy were $68 \%$ and $57 \%$, respectively, and the 1- and 2-year PFS rates were $38 \%$ and $25 \%$, respectively. No grade 4 or 5 toxicities were observed. Although an excellent LC was achieved, 9 (53\%) patients had distant disease progression in a median of 8 months after liver SBRT.

The most common metastatic sites for patients with breast cancer are the bones, lungs, liver, and brain. LM may be observed as the de novo or as the site of recurrence in approximately $15 \%$ of patients.[4] In a "Surveillance Epidemiology and End Results" database, $\mathrm{Wu}$ et al.[4] demonstrated that patients with BCLM have worse outcomes compared with lung or bone metastasis. Additionally, patients with recurrences isolated to limited number of organs $(<5)$, so called as oligometastasis, are considered to have better prognosis. [21] Oligometastasis has been first described by Hellman et al. in 1995.[21] Aggressive local treatments to oligometastatic sites may potentially reduce the risk of metastatic disease by removing the metastasis source, thereby improving outcomes.[22,23] Surgery, RFA, TACE, and RT are local treatment options for patients with oligometastasis.[6,24-26] Although surgery remains the treatment of choice in patients with BCLM, it could be applied only for a selective cohort of patients due to morbidity and mortality risks. TACE is a less invasive local treatment compared with surgery, and its efficacy for LC has been confirmed.[27] The reported OS, median disease-free survival, and response rates after TACE were 7.3-47.0 months, 2.9-17 months, and $7 \%-74 \%$, respectively. Pooled grade 3-4 side effects were reported up to $17 \%$.[27] The efficacy of RFA had been shown in various trials in the management of LM.[28-30] The response rates after RFA were 63\%$97 \%$, and the 5 -year survival rates ranged from $27 \%$ to $30 \%$. Although RFA is a minimally invasive method as an alternative to surgery, the reported morbidity and mortality rates were $9 \%-10 \%$ and $0.3 \%-2.2 \%$, respectively [28-30]. In our study, no patients experienced grade 4 or 5 toxicities, and our data on toxicity are consistent with the literature.

SBRT offers an alternative, non-invasive, and conservative approach for LM treatment. Several prospective and retrospective studies demonstrated the feasibility of SBRT for LM.[3,8-12,25] In these studies, LMs were treated in 1-12 fractions to a total dose of 18-60 Gy. The 2-year LC rates ranged from $66 \%$ to $90 \%$, and the 2 -year OS rates were $32 \%-81 \%$. Nevertheless, different patient selection, different histologies, and extrahepatic metastasis could cause the changes in OS and LC. In our study, patients with BCLM received 54 Gy in three fractions in a homogeneous group of cohort and dose-fraction schedule. The 1- and 2-year OS and PFS rates were $68 \%$ and $57 \%$ and $38 \%$ and $25 \%$, respectively.

The utility of PET-CT for assessing outcomes in patients with oligometastasis treated with SBRT was initially investigated by Solanki et al.[31] After a median follow-up of 14 months, they reported that PET 
response to SBRT enables metabolic tumor response in tumors non-measurable by CT, and higher SBRT doses correlate with long-term PET response in $31 \mathrm{pa}-$ tients with 58 lesions. Fendler et al.[20] investigated 80 patients with LM from colorectal cancer treated with $90 \mathrm{Y}$ radio embolization. They found that patients with a change in metabolic tumor volume or total lesion glycolysis have significantly longer survival than those without changes in PET parameters (92 vs. 49 weeks, $\mathrm{p}=0.006$ and 91 vs. 48 weeks, $\mathrm{p}=0.025$, respectively). [20] The changes in SUVmax in PET-CT in LM were investigated by Stinauer et al.[32] They reported that the estimated SUVmax decay half-time is 2 months. In our study, there was a significant difference between pre-SBRT SUV of LM 6.88 (range: 4.06-16.10) and post-SBRT SUV 0 (range: $0-5.30)(\mathrm{p}<0.001)$. CMR was observed in $14(82 \%)$ patients, PMR was observed in 2 (12\%) patients, and SMD/PMD was observed in $1(6 \%)$ patient at post-treatment PET-CT.

Our study has several limitations while interpreting the results. First, the retrospective nature of the study is the main limitation that may cause an inherent bias. Second, a small sample size restrained us from defining the prognostic factors affecting OS and PFS. Third, the follow-up time is relatively short for accurate decisions. Finally, the systemic treatment varied both before and after liver SBRT and absolutely influenced the treatment outcomes. Nevertheless, the present study is important because we analyzed only BCLM, only one type of dose fractionation with the same SBRT technique in each patient.

\section{Conclusion}

To the best of our knowledge, this is the first study to evaluate the impact of metabolic response measured by FDG-PET-CT in patients with BCLM treated with SBRT. SBRT is a conservative approach with similar LC rates compared with other invasive/minimally invasive local treatments with better toxicity profile. PET-CT is an effective tool for evaluating treatment response in patients with oligometastasis. Prospective trials are warranted for future directions and accurate decisions.

Ethical committee approval: This study was conducted in accordance with local ethical rules.

Peer-review: Externally peer-reviewed.

Conflict of Interest: None declared.

Authorship contributions: Concept - O.C.G., C.Ö.; Design - O.C.G., C.Ö.; Supervision - C.Ö.; Materials - N.T., B.A.Y.;
Data collection \&/or processing - N.T., B.A.Y.; Analysis and/ or interpretation - O.C.G.; Literature search - O.C.G.; Writing - O.C.Y., C.Ö.; Critical review - O.C.G., C.Ö.

\section{References}

1. Goodman KA, Kavanagh BD. Stereotactic Body Radiotherapy for Liver Metastases. Semin Radiat Oncol 2017;27(3):240-6.

2. Caivano D, Valeriani M, Russo I, Bonome P, DE Matteis S, Minniti G, et al. Stereotactic Body Radiation Therapy in Primary and Metastatic Liver Disease. Anticancer Res 2017;37(12):7005-10.

3. Goodman BD, Mannina EM, Althouse SK, Maluccio MA, Cárdenes HR. Long-term safety and efficacy of stereotactic body radiation therapy for hepatic oligometastases. Pract Radiat Oncol 2016;6(2):86-95.

4. Wu SG, Li H, Tang LY, Sun JY, Zhang WW, Li FY, et al. The effect of distant metastases sites on survival in de novo stage-IV breast cancer: A SEER database analysis. Tumour Biol 2017;39(6):1010428317705082.

5. Largillier R, Ferrero JM, Doyen J, Barriere J, Namer M, Mari V, et al. Prognostic factors in 1,038 women with metastatic breast cancer. Ann Oncol 2008;19(12):2012-9.

6. Adam R, Aloia T, Krissat J, Bralet MP, Paule B, Giacchetti $S$, et al. Is liver resection justified for patients with hepatic metastases from breast cancer? Ann Surg 2006;244(6):897-907.

7. Salama JK, Chmura SJ. The role of surgery and ablative radiotherapy in oligometastatic breast cancer. Semin Oncol 2014;41(6):790-7.

8. Guha C, Kavanagh BD. Hepatic radiation toxicity: avoidance and amelioration. Semin Radiat Oncol 2011;21(4):256-63.

9. Méndez Romero A, Wunderink W, Hussain SM, De Pooter JA, Heijmen BJ, Nowak PC, et al. Stereotactic body radiation therapy for primary and metastatic liver tumors: A single institution phase i-ii study. Acta Oncol 2006;45(7):831-7.

10. Milano MT, Katz AW, Zhang H, Okunieff P. Oligometastases treated with stereotactic body radiotherapy: long-term follow-up of prospective study. Int J Radiat Oncol Biol Phys 2012;83(3):878-86.

11. Rusthoven KE, Kavanagh BD, Cardenes H, Stieber VW, Burri SH, Feigenberg SJ, et al. Multi-institutional phase I/II trial of stereotactic body radiation therapy for liver metastases. J Clin Oncol 2009;27(10):1572-8.

12. Scorsetti M, Arcangeli S, Tozzi A, Comito T, Alongi F, Navarria $P$, et al. Is stereotactic body radiation therapy an attractive option for unresectable liver metastases? A preliminary report from a phase 2 trial. Int J Radiat Oncol Biol Phys 2013;86(2):336-42.

13. Higuchi I, Yasuda T, Yano M, Doki Y, Miyata H, Tat- 
sumi M, et al. Lack of fludeoxyglucose F 18 uptake in posttreatment positron emission tomography as a significant predictor of survival after subsequent surgery in multimodality treatment for patients with locally advanced esophageal squamous cell carcinoma. J Thorac Cardiovasc Surg 2008;136(1):205-12.

14. Onal C, Reyhan M, Parlak C, Guler OC, Oymak E. Prognostic value of pretreatment 18F-fluorodeoxyglucose uptake in patients with cervical cancer treated with definitive chemoradiotherapy. Int J Gynecol Cancer 2013;23(6):1104-10.

15. Downey RJ, Akhurst T, Gonen M, Vincent A, Bains MS, Larson S, et al. Preoperative F-18 fluorodeoxyglucose-positron emission tomography maximal standardized uptake value predicts survival after lung cancer resection. J Clin Oncol 2004;22(16):3255-60.

16. Wahl RL, Jacene H, Kasamon Y, Lodge MA. From RECIST to PERCIST: Evolving Considerations for PET response criteria in solid tumors. J Nucl Med 2009;50 Suppl 1:122S-50.

17. Onal C, Oymak E, Findikcioglu A, Reyhan M. Isolated mediastinal lymph node false positivity of $[18 \mathrm{~F}]$-fluorodeoxyglucose-positron emission tomography/computed tomography in patients with cervical cancer. Int J Gynecol Cancer 2013;23(2):337-42.

18. Esposito M, Maggi G, Marino C, Bottalico L, Cagni E, Carbonini C, et al. Multicentre treatment planning inter-comparison in a national context: The liver stereotactic ablative radiotherapy case. Phys Med 2016;32(1):277-83.

19. Berkovic P, Gulyban A, Nguyen PV, Dechambre D, Martinive P, Jansen N, et al. Stereotactic Robotic Body Radiotherapy for Patients With Unresectable Hepatic Oligorecurrence. Clin Colorectal Cancer 2017;16(4):349-57.e1.

20. Fendler WP, Philippe Tiega DB, Ilhan H, Paprottka PM, Heinemann V, Jakobs TF, et al. Validation of several SUV-based parameters derived from $18 \mathrm{~F}$ FDG PET for prediction of survival after SIRT of hepatic metastases from colorectal cancer. J Nucl Med 2013;54(8):1202-8.

21. Hellman S, Weichselbaum RR. Oligometastases. J Clin Oncol 1995;13(1):8-10.

22. Alongi F, Arcangeli S, Filippi AR, Ricardi U, Scorsetti M. Review and uses of stereotactic body radiation therapy for oligometastases. Oncologist 2012;17(8):1100-7.
23. Halsted WS. I. The Results of Radical Operations for the Cure of Carcinoma of the Breast. Ann Surg 1907;46(1):1-19.

24. Eichler K, Jakobi S, Gruber-Rouh T, Hammerstingl R, Vogl TJ, Zangos S. Transarterial chemoembolisation (TACE) with gemcitabine: phase II study in patients with liver metastases of breast cancer. Eur J Radiol 2013;82(12):e816-22.

25. Milano MT, Katz AW, Muhs AG, Philip A, Buchholz DJ, Schell MC, et al. A prospective pilot study of curative-intent stereotactic body radiation therapy in patients with 5 or fewer oligometastatic lesions. Cancer 2008;112(3):650-8.

26. Veltri A, Gazzera C, Barrera M, Busso M, Solitro F, Filippini $\mathrm{C}$, et al. Radiofrequency thermal ablation (RFA) of hepatic metastases (METS) from breast cancer (BC): an adjunctive tool in the multimodal treatment of advanced disease. Radiol Med 2014;119(5):327-33.

27. Wang M, Zhang J, Ji S, Shao G, Zhao K, Wang Z, et al. Transarterial chemoembolisation for breast cancer with liver metastasis: A systematic review. Breast 2017;36:25-30.

28. Curley SA, Marra P, Beaty K, Ellis LM, Vauthey JN, Abdalla EK, et al. Early and late complications after radiofrequency ablation of malignant liver tumors in 608 patients. Ann Surg 2004;239(4):450-8.

29. Kong WT, Zhang WW, Qiu YD, Zhou T, Qiu JL, Zhang $\mathrm{W}$, et al. Major complications after radiofrequency ablation for liver tumors: analysis of 255 patients. World J Gastroenterol 2009;15(21):2651-6.

30. Livraghi T, Solbiati L, Meloni MF, Gazelle GS, Halpern EF, Goldberg SN. Treatment of focal liver tumors with percutaneous radio-frequency ablation: complications encountered in a multicenter study. Radiology 2003;226(2):441-51.

31. Solanki AA, Weichselbaum RR, Appelbaum D, Farrey K, Yenice KM, Chmura SJ, et al. The utility of FDGPET for assessing outcomes in oligometastatic cancer patients treated with stereotactic body radiotherapy: a cohort study. Radiat Oncol 2012;7:216.

32. Stinauer MA, Diot Q, Westerly DC, Schefter TE, Kavanagh $\mathrm{BD}$. Fluorodeoxyglucose positron emission tomography response and normal tissue regeneration after stereotactic body radiotherapy to liver metastases. Int J Radiat Oncol Biol Phys 2012;83(5):e613-8. 